\title{
Demand for Healthcare Services in Nigeria: A Multivariate Nested Logit Model
}

\author{
H. Eme Ichoku* and Murray Leibbrandt**
}

\begin{abstract}
The object of this paper is to explain the healthcare decision process and the factors that influence medicare demand decisions of Nigerian households during a period of economic depression. It is based on a sample from a small-area analysis focusing on a relatively homogenous group. The objective of the study involved the estimation of the parameters of the demand for healthcare services in order to understand the nature of healthcare choices and the pathways to those choices that Nigerian households make under dire economic circumstances. These demand parameter estimates are considered valuable inputs into healthcare policy. Yet, to date, there is no sufficient information on the vital factors that shape households' utilization of medicare services nor is there sufficient information on the relative importance of healthcare alternatives available to them. This is the knowledge gap that this study hopes to fill. The nested logit model was found to be an appropriate functional form for the analysis.
\end{abstract}

Résumé: Le présent article a pour objet d'expliquer le processus de prise de décisions et les facteurs qui influent sur les décisions concernant les besoins en soins médicaux des ménages nigérians durant une période de dépression économique. Il repose sur l'analyse d'un échantillon de ménages provenant de secteurs restreints, notamment d'un groupe relativement homogène. L'étude a pour objectif d'analyser les paramètres de besoins en services de soins de santé pour comprendre les différentes possibilités qui s'offrent aux ménages nigérians et les choix qu'ils sont amenés à faire dans des conditions économiques très dures. L'estimation des paramètres afférents à ces besoins est censée être un élément important pour l'élaboration d'une politique de soins de santé. Or, les données sur les facteurs essentiels qui influencent le recours aux services de soins de santé par les ménages, sont actuellement insuffisantes, tout comme celles

\footnotetext{
* Department of Economics, University of Nigeria, Nsukka and Health Economics Unit, University of Cape Town; e-mail: hichoku@yahoo.com. The author acknowledges financial support from the Swedish International Development Agency (SIDA).

** School of Economics, University of Cape Town; e-mail: mleibbra@commerce.uct.ac.za
} 
concernant l'importance des différents choix qui s'offrent à eux. La présente étude vise à combler ces lacunes et, pour ce faire, utilise un modèle de logit imbriqué considéré comme étant une formule fonctionnelle appropriée.

\section{Introduction}

A healthcare system that meets the needs of a developing country like Nigeria presupposes a thorough understanding not only of the reasons why the present healthcare system fails to deliver healthcare to the people but also the dynamics of healthcare decision processes of households to which the healthcare system ought to respond. Such a clear understanding will help in redefining the objectives of national healthcare policy and those of the active players in the healthcare delivery system.

For most Nigerian households the decade of the 1990s was a very difficult period. The ripple effects of macroeconomic policies of previous decades, such as the Structural Adjustment Programme (SAP), combined with political instability in the country to send devastating economic shocks across the country (Egwu, 1998). There was rapid decline in most major macroeconomic indices. The economy that was growing at the rate of 7.5 per cent in the 1970s recorded, on average, zero growth for the greater part of the decade. Per capita income fell from $\$ 860$ in the early 1980 s to below $\$ 300$. The national currency, the naira, was devalued by more than 11,000 per cent. External debt grew to over $\$ 30$ billion or $\$ 200$ per capita at the end of the 1990s (Green, 2001). This represented about 144 per cent of 1993 GDP of the country (Kpakol, 2001), Debt service ratio was as high as 71 per cent in some years within that decade (Obadan, 2001; Ajayi, 2001). For the greater part of the 1990s inflation stayed above 50 per cent and industrial capacity utilization was as low as 30 per cent in some years. Political instability brought insecurity and social welfare to intolerable levels. It has been estimated that about $\$ 100$ billion left the country in the form of capital flight due to political instability (Soludo, 2001). Social infrastructure and physical environment have deteriorated.

In the face of continued severe economic and social crises, many households could no longer afford the basic necessities of life for their members. The ability of households to cope with adverse economic conditions has been strained. Difficult trade-offs continue to be made in an attempt to keep households afloat. Nutritional intake and other health-enhancing inputs into the household health production function, such as leisure and sports, have either been reduced or eliminated altogether from the household schedule. These social upheavals have led to breakdowns in the health of individuals, households and communities. 
The advances made against some of the communicable and preventable diseases during the period of economic growth of the 1970s and early 1980s have been eroded (Pearce and Falola, 1994). Because of economic barriers many households can hardly afford medical care. The reporting of illnesses is delayed until the illness becomes severe because the cost of medical care has to be weighed against other pressing household needs such as food and education.

Under conditions such as these, children are usually the most vulnerable group, given their physical weakness (Vogel, 1988). It has been estimated that about 200,000 Nigerian children die every year from diarrhoea-related illnesses while about 650,000 people are afflicted by Guinea worm (Ayogu, 1999). The struggle by parents to provide for the household especially among poor households means reallocation of time and resources. Parents are often away from home for the greater part of the day. Adults have less time to care for children. These children become victims of hunger and disease. Their physical and mental development is at risk of impairment.

This paper focuses on a local government area in Nigeria, the Nsukka local government area. It uses data generated from the area in a recent household survey to analyse the pathways of households' healthcare decisions as well as the factors that influence their utilization of healthcare facilities under depressed economic conditions. The recognition that households' healthcare decision is not a once-off maximization procedure is an important contribution of this paper. Furthermore, the focus on small-area analysis is considered important since it makes for greater estimation precision. The community is relatively homogenous with similar cultural and behavioural tendencies. The purpose is primarily to avail healthcare policy-makers and planners and other healthcare providers in Nigeria of some healthcare demand parameter estimates that are necessary for effective policy-making.

Quite a number of research studies have been conducted in this area internationally in the context of developing countries (Heller, 1982; Akin et al., 1981; Mwabu, 1984; 1986; Gertler et al., 1987; Gertler and van der Gaag, 1990; Ellis and Mwabu, 1991; Bartholome and Vosti, 1995; Dow, 1996). However, econometric methodologies and findings have differed widely. While many have used the multinomial logit specification for capturing the underlying data generation process in the demand for healthcare, some others have used the probit model. It is clear, however, that the nested logit model comes closer to representing the healthcare decision process than any of the other models so far used in modelling healthcare demand. We have, therefore, adopted the multivariate nested logit model developed by McFadden (1981) for the transportation industry, but which has been successfully applied in healthcare demand studies 
(see for example, Ellis and Mwabu, 1991). In a certain sense this work is an extension of the latter.

\section{Analytical Framework}

Much of the recent progress in healthcare demand research is due to the theoretical insights of Grossman (1972). Essentially, Grossman's proposition is that the demand for healthcare is a derived demand. Health is demanded as an argument in the direct utility function of the individual as both a source of utility in itself and as a capital or investment good since it determines the amount of time available to the individual for the production of other goods and services.

Extending this idea of health as a basic commodity, Wagstaff (1986) shows that Grossman's model builds on the fundamental assumptions of neoclassical microeconomics, namely, a downwards-sloping demand curve, a set of convex indifference curves, a budget constraint and a production function that is subject to diminishing marginal returns. A downward-sloping demand curve implies that the shadow price of health expenditures is not only the price the household pays the healthcare provider but also the index of all other consumption goods that are forgone. A convex utility function implies that trade-offs have to be made between the quantity of health producing goods and the quantity of other consumption goods that are available to the household.

Since the household budget is necessarily limited, choices must be made with a view to maximizing the total utility of the household subject to budget constraints. If a household member falls ill, the utility that the household would derive from giving the individual medical treatment that produces improvement in health status has an opportunity cost in terms of the reduction of the quantity of other consumption goods available to the household. Therefore, given its resources, the household has to make a decision whether to seek medical care or not for this member depending on which decision is consistent with its utility maximization objectives. If a decision is made to seek medical care, a further decision has to be made regarding from which of the available healthcare providers this treatment is to be obtained. A feasible option is to treat the person at home; that is, home care. Since the household is assumed to be rational and inclined to maximizing its utility, it has to weigh the quality of health gained from a given provider against the cost of seeking care from that provider or category of providers.

Let us consider, for example, the utility maximizing behaviour of a household who faces a choice between two health providers. Subject to resource constraints, this household will have a utility function that 
measures the desirability of a given option. The utility functions may be specified as:

$$
\left.\begin{array}{l}
U_{0}+\mu_{0}+\varepsilon_{0} \\
U_{1}+\mu_{1}+\varepsilon_{1}
\end{array}\right]
$$

for alternatives 0 and 1 respectively. Where $\mu$ is a set of household demographic (and healthcare production function) variables and other variables with their associated parameters. The error term $\varepsilon$ captures the unobservables and measurement errors about the characteristics of the household and misjudgments about the attributes of the facilities. If the households were sampled randomly from a population with common socio-economic characteristics $x$ and assuming that the same providers or facilities are available then, following Domencich and McFadden (1975, pp. 50-52), the utility function can be said to be stochastic. In other words, the error term is randomly distributed. This is clearly so because the value of the utility function will depend on the household drawn at random from the population and the particular provider alternative chosen. Formally, then, the choice of health facility 1 over facility 0 is

$$
U_{i 1} \succ U_{i 0}
$$

The probability function may be expressed in the form:

$$
P\left(y_{i}=1 \mid \mu\right)=\operatorname{Prob}\left(\varepsilon_{i 0}-\varepsilon_{i 1} \prec \mu_{i 0}-\mu_{i 1}\right)
$$

where $y=1$ may be defined as the probability $(P)$ that the utility the $i$ th household derives from choosing alternative 1 is greater than the utility it derives from choosing alternative 0 given the set of identifying socioeconomic characteristics of the household; and $y=0$ to be the probability otherwise.

The event that a household drawn randomly from the population with the same household socio-economic characteristics chooses $U_{i 1}$ over $U_{i 0}$ then gives the probability function

$$
P\left(y_{i}=1 \mid \mu\right)=\operatorname{Prob}\left(U_{i 1} \succ U_{i 0}\right)
$$

Assumptions made about the variance of $\varepsilon\left(=\varepsilon_{i 0}-\varepsilon_{i 1}\right)$ in Equation (3) give rise to several forms of probabilistic models. For example, in the probit model it is assumed that the mean of $\varepsilon$ is 0 and the variance is 1 which gives a normal distribution. In the logistic model the mean is 0 and the variance is assumed to be $\pi^{2} / 3$. 
The stochastic term

$$
\varepsilon=\left(\varepsilon_{i 0}-\varepsilon_{i 1}\right)
$$

is assumed to be independently and identically distributed. This property guarantees that distribution is consistent with random utility maximization (RUM) that is a prerequisite for welfare analysis. This distribution is said to follow Type I extreme value distribution or log Weibull distribution specified as

$$
\operatorname{Prob}\left(\varepsilon_{i 0} \prec \varepsilon_{i 1}\right)=\exp [-\exp (-\varepsilon)]
$$

This distribution resembles the normal distribution. It is bell-shaped. However, it has a thicker tail on the right and a thinner left tail. It has a mode at 0 , mean at 0.575 and variance of 1.622 in contrast to normal distribution with variance $=1$.

\section{The Nested Logit Model}

For the case of multiple choice indexed over $k,(k=0,1,2, \ldots K)$, we may define $y_{i k}=1$ if the $i$ th household chooses the $k$ th healthcare provider and 0 if not. A number of researchers have used the multinomial logit to estimate the parameters of such models. But such applications are clearly inappropriate.

The strength of the multinomial model (though) is that the addition of a new alternative while decreasing the probability that an alternative is chosen does not alter the relative odds of the existing ones. In other words, the ratio of the odds of choosing facility 0 to the odds of choosing facility 1 does not change because of the addition of facility 2. However, the main weakness is that for the relative odds of alternative 0 to alternative 1 to remain the same, the new alternative must be perceived as completely distinct and independent. Furthermore, the model implies that the effect of the introduction of the new alternative on the existing ones is the same. That is, the model implies constant cross-elasticity of demand in which substitution is difficult (Domencich and McFadden, 1975).

A major conclusion to be drawn from the above is that unless the alternatives are completely dissimilar, the multinomial logit model cannot be applied. To put it another way, unless the error terms in the choices are independently distributed, the multinomial logit model would be inappropriate. The assumption that the error terms are completely independently distributed is what Domencich and McFadden (1975) 
called independence of irrelevant alternative (IIA). Amemiya (1981) shows that in many studies the absence of IIA cannot be assumed.

The motivating idea behind the nested logit model is a sequential choice structure in which the economic agent is assumed to choose between independent classes of utilities at each level. While the correlation between the stochastic terms in the independent classes are assumed to be zero, the error terms within the classes are allowed to be non-zero. How does this solve the problem of correlation among the error terms? The assumption here is that mean utility of 'best' alternative in each class approximates the maximum utility in that class. For example, a household weighs the utility from home care against the 'best' of the two alternatives in the class of formal providers.

Using the tree analogy to illustrate, it is assumed that the following conditions obtain.

- Trunk: A household reports sick.

- Limb: Conditional upon a member reporting ill, the household either seeks treatment or does not seek treatment.

- Branch: Conditional upon the decision to seek healthcare service, it either seeks formal care from a professional healthcare provider/ facility or informal care (i.e., the production of healthcare at home).

- Twig: Conditional upon the decision to seek professional care, it chooses from among the professional providers (government hospital/ clinic $[$ Pub.H/C], private hospital/clinic [Prvt.H/C], traditional medicine $[\mathrm{T} / \mathrm{Med}]$ and pharmaceutical/patent medicine store $[\mathrm{P} / \mathrm{Med}])$

Although the error terms within the class of formal providers may tend to correlate, the error terms in the formal and informal have zero correlation. This model gives rise to a tree-like structure of decision process with a trunk, limbs, branches and twigs as illustrated in Figure 1.

Figure 1: A sequential choice structure of demand for healthcare

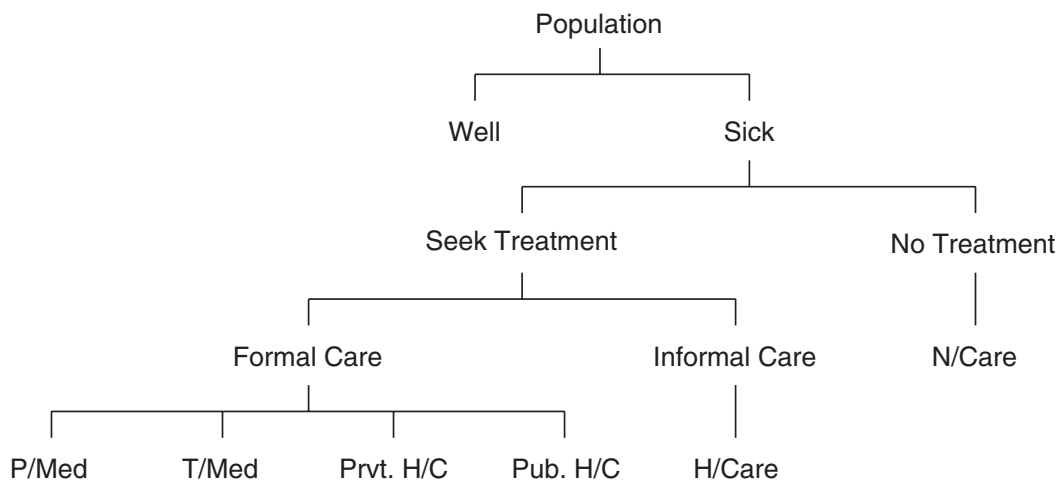


As the focus of this study is on the choices that households make when they are confronted with sickness, we ignore the trunk with the 'Well' population and concentrate on the trunk with the 'Sick' population.

There are three decision nodes on the trunk with the sick population representing the three-level nested model. At the lowest level is the choice among the available categories of health facilities (the twigs) determined by a set of household demographic and other variables. This is nested on the decision to seek formal care or informal care. The decision to seek formal or informal care is nested on the third level of decision: whether or not to seek treatment. The decision to seek treatment or not is nested on the fourth level: Well or Sick. This fourth level is outside our consideration here. The decision at each of these three levels can be modelled as a separate utility function. That is, the household may be seen as taking an independent decision at each decision node or point. The decision whether to treat this sickness or not may be modelled as a binary logit decision. Suppose the household takes the decision to treat this illness, then at the second stage the household takes another decision whether to treat it at home without consulting any medical expert (informal care) or to seek the help of a medical professional (formal care). This level, again, may be modelled as a logit model. Finally, suppose the household decides to consult a medical expert, it has to decide which of the available professional facilities to consult. Here the household is deemed as making a discrete choice among the facilities. Each of these decisions is taken with a view to maximizing the household's utility function. Domencich and McFadden (1975) show that this decision structure provides a way out of the independence of irrelevant alternative (IIA) assumption because the decision at every level is deemed to be between distinct classes while within-class decision error terms are allowed to correlate. The model is also consistent with the strict utility model.

While it may be normal to consider the household as taking a separate decision at each step, it is also possible to consider the decisions as taking place simultaneously (Ellis and Mwabu, 1991). That is, the household takes all the three decisions in one pass to maximize its utility function. In the latter case, the unconditional utility function may be specified as

$$
U_{i j k}=U\left(X_{i j k}+Y_{i j}+Z_{i}\right)+\varepsilon_{i j k}+\varepsilon_{i j}+\varepsilon_{i}
$$

where $X_{i j k}$ represents the set of observed attributes that vary with twig, branch and limb. The number of twigs $k$ is indexed as $k=1,2, \ldots K$ for all possible options at that level. (In this model $K=6$.) It is to be understood then that any attribute that varies among branches will lead to variation among the limbs and trunk. It is further to be understood that the set of 
variables represented by $X_{i j k}$ influences the household's decision about which facility to seek healthcare from. $Y$ represents the set of attributes that varies according to branch. The number of branches may be indexed as $j=1,2, \ldots J$ (here, $J=2$ ). Any attributes that vary among the branches will imply variation between the limbs. $Z$ represents the set of attributes that characterize the tree at the limb level. The number of limbs may be indexed as $i=1,2 \ldots S$ (here $S=2$ ). The residuals are captured as $\varepsilon_{i j k}, \varepsilon_{i j}$ and $\varepsilon_{i}$ respectively. They represent the influence of variables that may have been excluded from the model, variations in household perceptions, habits, imperfections in household judgment about choices that maximize its utility.

In the nested logit model the error terms are assumed to follow a multivariate extreme value distribution or generalized extreme value (GEV) distribution which allows for dependence among the choices in a class. McFadden (1981) defines this distribution as

$$
F\left(\varepsilon_{1}, \varepsilon_{2}, \ldots, \varepsilon_{m}\right)=\exp \left\{-G\left[\exp \left(-\varepsilon_{1}\right), \exp \left(-\varepsilon_{2}\right), \ldots, \exp \left(-\varepsilon_{m}\right)\right]\right\}
$$

where

$$
G\left(\exp \left(\mu_{1}\right), \exp \left(\mu_{2}\right), \ldots, \exp \left(\mu_{m}\right)\right)
$$

is a function of stochastic utility satisfying the condition

$$
\left(\mu_{1}, \mu_{2}, \ldots \mu_{m}\right) \geq 0
$$

and is homogenous of degree 1 . For the case of three alternatives in which alternative 1 is distinct and alternatives 2 and 3 are similar, the resulting probability, following Maddala (1983), will be

$$
P\left(y_{i}=1 \mid \mu\right)=\frac{\exp \left(\mu_{1}\right)}{\exp \left(\mu_{1}\right)+\exp \left(\mu_{2}\right)+\exp \left(\mu_{3}\right)}
$$

The probability for alternative 2 will be

$$
P\left(y_{i}=2 \mid x\right)=\frac{\exp \left[\frac{\mu_{1}}{(1-\sigma)}\right]\left(\exp \left[\frac{\mu_{2}}{(1-\sigma)}\right]+\exp \left[\frac{\mu_{3}}{(1-\sigma)}\right]\right)}{\exp \left(\mu_{1}\right)+\exp \left(\mu_{2}\right)+\exp \left(\mu_{3}\right)}
$$

The probability of alternative 3 will resemble that of 2 . The correlation coefficient $\sigma$ is a measure of the correlation between the alternatives. As a measure of correlation, its value lies between 0 and 1 . 
The utility function may then be specified as

$$
\begin{aligned}
U_{i j k}=\left(\mu_{i j k}\right)+\varepsilon_{i j k}+\varepsilon_{i j}+\varepsilon_{i}= & \left(\beta^{\prime} X_{i j k}+\alpha^{\prime} Y_{i j}+\gamma^{\prime} Z\right) \\
& +\varepsilon_{i j k}+\varepsilon_{i j}+\varepsilon_{i}
\end{aligned}
$$

Note that $\alpha^{\prime} Y$ and $\gamma^{\prime} Z$ are included in the specification because of the possible impact of the variables specified at the choice of facility level $\left(X_{i j k}\right)$ on these higher levels.

The vector $X_{i j k}$ represents attributes that vary with facility and so vary also with branch and limb. $Y_{i j}$ is the vector of attributes that vary with the branch (formal/informal treatment) and so vary also with limb. $Z_{i}$ represents the set of attributes that vary with limb (treatment/no treatment). $\beta, \alpha$ and $\gamma$ are vectors of unknown parameters to be estimated. The probability that a household chooses option $k$ in branch $j$ in limb $i$ may be expressed as:

$$
P_{i j k}=P_{k \mid i j} \times P_{j \mid i} \times P_{i} \quad \text { or } \quad P_{i j k}=\frac{\exp \left(\mu_{i j k}\right)}{\sum_{l} \sum_{m} \sum_{n} \exp \left(\mu_{l m n}\right)}
$$

where the subscripts $l, m$ and $n$ tell us the number of choices available at the limb, branch and twigs respectively. For a given household the value $P_{i j k}$ may be considered as its unconditional maximized utility. It is its contribution to the overall likelihood function of the entire sample.

The conditional probability $P_{k \mid i j}$ involves the impact of the set of attributes $X_{i j k}$ at only the level of choice among the facilities. The set of parameters $\beta$ estimates this impact at the branch level of choice among facilities. The conditional probability of $k$ given $j$ and $i$ may be expressed as

$$
P_{k \mid i, j}=\frac{\exp \left(\beta^{\prime} x_{i j k}\right)}{\sum_{n} \exp \left(\beta^{\prime} X_{i j n}\right)}
$$

Following Maddala (1983), we define the inclusive value at the branch level to be the log of the sum of $\exp \left(\beta^{\prime} X_{i j n}\right)$ which is the denominator in Equation (13). This has been interpreted to mean the expected contribution to overall utility of the choice made at the preceding level (Ellis and Mwabu, 1991).

To formalize, we specify this value as

$$
I_{i j}=\ln \left[\sum_{n} \exp \left(\beta^{\prime} X_{i j n}\right)\right]
$$

Equation (14) specifies the branch inclusive value and has a coefficient that lies between 0 and 1 . We can therefore express it as: 


$$
\ln \left[\sum_{n} \exp \left(\beta^{\prime} X_{i j k}\right)\right]=\left(1-\sigma_{k}\right) I_{i j}
$$

The conditional probability that a household seeks formal care given that it seeks treatment may be expressed as

$$
P_{j \mid i}=\frac{\exp \left(\alpha Y_{i j}+I_{i j}\right)}{\sum_{m} \exp \left(\alpha^{\prime} Y_{i m}+I_{i m}\right)}
$$

The inclusive value at the limb level is then the expression

$$
\ln \left(\sum_{m} \sum_{n} \exp \left(\beta^{\prime} X_{i m n}+\alpha^{\prime} Y_{i m}\right)\right)=\ln \left(\sum_{m} \exp \left(\alpha^{\prime} Y_{i m}+I_{i m}\right)\right)
$$

The inclusive value parameter at this level also lies within the $0-1$ range and thus we denote it as $\left(1-\sigma_{j}\right) J$. Where $J$ denotes the right-hand expression in the inclusive value identity stated in (17).

Finally, the probability that a household reported sickness is given by

$$
P_{i}=\frac{\exp \left(\gamma^{\prime} Z_{i}\right)+\ln \left[\sum_{l} \exp \left(\alpha^{\prime} Y_{i l}+I_{i l}\right)\right]}{\sum_{l} \exp \left(\gamma^{\prime} Z_{l}\right)+\ln \left[\sum_{l} \exp \left(\alpha^{\prime} Y_{l}+I_{l}\right)\right]}
$$

Replacing the second expression in both the numerator and denominator with $J$, this last equation can be expressed more compactly as

$$
P_{i}=\frac{\exp \left(\gamma^{\prime} Z_{l}\right)+J_{l}}{\sum_{l} \exp \left(\gamma^{\prime} Z_{l}\right)+J_{l}}
$$

This third level inclusive value parameter is expected to be unity because the probability of reporting ill for a household that reported ill is one, since we are dealing with only households that reported illness.

The inclusive value parameters are not only important in themselves, they are even more important because they provide a specification test for the overall fit of the model. McFadden (1981) shows that a necessary and sufficient condition for this model to be consistent with rational utility maximization is that the inclusive value parameter must lie in the unit interval. If the estimated inclusive value parameter equals 1.0, then that is an indication that the appropriate functional form is one level model. However, if the estimated inclusive value parameter lies outside the range $0-1$, Maddala (1983) suggests that that is an indication that the model does not suit the data generating process. In other words, the model does not fit the behaviour pattern of households from which the data was generated. The condition requiring the estimated inclusive value 
parameters of the model to lie between $0-1$ is apparently crucial if we are to ensure that the model approximates the data generating process.

The log likelihood function to be estimated is given by:

$$
\ln L_{k \mid i j}=\sum_{k=0}^{K} D_{k \mid i j} \ln P_{k \mid i j}
$$

where $D_{i k}$ is a dummy that takes on 1 if a household chooses facility $k$ and 0 if not.

The dependent variable at the utility function level of the estimation is FACILITY. This is an indicator variable with six categories that include Nocare, Homecare, Public Hospitals/Clinics, Private Hospitals/Clinics, Traditional Medicare, and Pharmaceutical/Patent Medicine Stores. This implies that each observation will have five dummies. The indicator is 1 if a particular facility is chosen or 0 otherwise. Thus the probability that $F A C I L I T Y=1$ is an index of choice made.

\section{Data}

The data for this study were generated from a household survey conducted in the Nsukka local government area (LGA) between January and February 2000. The Nsukka LGA is located in the northernmost part of Enugu State, south-east Nigeria. It comprises 15 communities with the following populations: Anuka (776), Okutu (4,022), Ibeagwagu $(1,304)$, Okpuje $(9,259)$, Ibeagwani $(9,443)$, Okpaligbo $(2,500)$, Obukpa $(20,056)$, Aloruno (6,530), Edem (16,661), Obimo (12,753), Lejja $(15,325)$, Edeoballa 14,368), Opi $(25,384)$, Ehalumona $(36,129)$ and Nsukka $(79,913)$. Total population as at 1996 was 254,422 . The LGA spans an area of less than $1,000 \mathrm{sq} . \mathrm{km}$. Compared to other parts of south-eastern Nigeria, the LGA is relatively poor. The majority of the population is engaged in farming, crafts and other rural occupations. Nsukka itself is a semi-urban town with substantial trading and transportation activities that serve the population of the University of Nigeria located in this area.

There are a number of health facilities that serve the communities in this LGA. At the time of the interview, there were two general hospitals run by the Enugu State Government, and 20 primary healthcare clinics run by the Nsukka Local Government. There were 20 private and mission hospitals, 25 private maternity centres, 11 private clinics and a medical centre located inside the university. There were also a couple of pharmacy shops and several patent medicine shops in almost every nook and cranny of the communities. Traditional medicine healers constitute a significant proportion of healthcare suppliers in the health market of this area. 
From an epidemiological perspective, the most prevalent diseases as at the time of the survey were malaria, typhoid fever, tuberculosis and children's diarrhoea. These were reported in many of the health facilities visited and confirmed by the Head of Department of the Local Government Department of Health.

\subsection{Sampling Strategy}

A two-stage sampling design was adopted for the sampling process. The first stage was the selection of the clusters to be sampled. The second stage was the selection of the households to be interviewed. For the selection of the clusters, each of the 15 autonomous communities was assumed to constitute a natural cluster. The Nsukka community, with a population of about 80,000 and a fairly developed social infrastructure, made up the urban cluster while the rest of the other communities were rural.

Although simple random sampling is generally regarded as an ideal, however, there are often compelling reasons for choosing other sampling methods that may be more cost effective than simple random sampling. As Deaton (1998) notes, apart from cost considerations, the accuracy of an econometric estimate can sometimes be enhanced by the researchers' prior information about the population being surveyed. Such prior knowledge can assist the researchers in designing an effective method that will strengthen the efficiency of the statistical inference about the population under study.

In designing this survey, the two-stage cluster sampling was considered optimal for the data collection. While cost consideration was important, there were other advantages that came to the fore in selecting the method. From the cost perspective, it was considered more cost effective to assign a group of field workers to a village community where households live in contiguous compounds rather than have them travel for long distances to interview households that live far apart.

There is another advantage of the method adopted in this survey; since households that were interviewed lived in clusters, it was easy to collect village level information. For example, it was easy to estimate the distance to the health facilities where a majority of the households living within the cluster went to obtain treatment. Furthermore, it was easy to collect market prices of consumption goods from the communities.

Of the 15 communities that made up the local government, ten were picked at random for the survey. From the chosen ten communities households were selected in proportion to the population size of the communities and then interviewed. The ten cluster communities that 
were picked in the random sample were Anuka, Ibeagwagu, Ibeagwani, Aloruno, Edem, Obimo, Lejja, Edeoballa, Opi and Nsukka.

Household and community level questionnaires were the main instrument used for the collection of data. Facility questionnaires were also administered to some health facilities. The questions were generally structured questions in which multiple options were provided to the respondents. The questions were made as simple as possible. The respondents were required simply to select the appropriate responses from a list of possible responses. The first part of the interview revolved around household demographic structure, the sickness variables and problems associated with healthcare decisions. The next part was concerned with economic variables. These included questions about household income and expenditure. The last part of the question was reserved for the operators of health facilities.

In order to meet the requirement for maximum likelihood estimation, about 1,008 households with about 6,800 individuals were interviewed. However, during the process of cleaning the data set, about 71 households were eliminated. There were 937 households remaining. Most of those eliminated were on the ground of inconsistencies in their responses. Each community cluster was sampled in proportion to its population.

The interviewers were graduate students of the university who had been trained for this purpose. They spoke the same language (Igbo) as the people though some were not very familiar with the Nsukka dialect of the Igbo language. They were accompanied with assistants from the local communities. The latter were versed in the nuances of local dialects and did on-the-spot renditions as the need arose. The respondents were generally open and less economical with responses though there were still a number of cases where prospective respondents were unwilling to volunteer information because they were suspicious of the purpose of the interview. This was in spite of assurances from native rulers to whom the purpose of the interview had been explained.

To begin the interview a general permission was sought for and obtained from the local government and the head of department of healthcare services in the Nsukka Local Government. Apart from the permission from these local government authorities, before the interview took place in any community the team of interviewers visited the local chief in the area they were going to work to inform him of the purpose of the interview. They also had to ask for his blessing as the tradition of the people required.

Whenever possible the interview was conducted with the best informed member of the household on the subject matter. For example, the mother of the house was generally requested to respond to questions on household food expenditure. Before the main interviews started, some pre-test 
interviews were conducted. The purpose was to test the respondents' understanding of the questions and experience what difficulties might arise during the actual interviews. These difficulties were incorporated in the wording that the final instrument used.

In terms of the period of coverage, most of the questions were focused on household health and economic decisions within the month preceding the interview. Indeed, except for questions about household expenditure on durables, the rest were limited to this period. The reason for the focus on the preceding one month is that a number of studies have shown that household expenditures and consumption tend to diminish the longer the recall period (Scott and Amenuvegbe, 1990; Deaton 1997).

\subsection{Variable Definitions}

The following variables are included in the model:

The dependent variable at the utility function level of the estimation is FACILITY. This is an indicator variable with six categories that include: Nocare, Homecare, Public Hospitals/Clinics, Private Hospitals/Clinics, Traditional Medicare, and Pharmaceutical/Patent Medicine shops. The indicator is 1 if a particular facility is chosen and 0 otherwise. Thus the probability that $F A C I L I T Y=1$ is an index of choice made.

- LOC: Location dummy indicating whether the household is located within the semi-urban or rural community.

- HH_SIZE: Defined as the number of people who live under the same roof at least 15 days in a month for a period of one year and share food from a common source.

- DISTANCE: This is the distance a household seeking healthcare has to travel to reach the chosen healthcare facility. It is measured in kilometres.

- $S_{-} A G E$ : Age of the ill person at the last birthday.

- SEVERITY: This variable measures the severity of the illness. It is proxied by the number of days the ill person was unable to carry out his or her normal activities within the month preceding the interview.

- $W_{-} T I M E$ : The amount of time the patient had to wait in order to obtain treatment from the chosen healthcare provider.

- TMTCOST: This is the financial cost of obtaining treatment from the provider. It excludes the cost of transportation.

- PCFDX: The per capita food expenditure of the household.

- INCOME: The household's estimated total financial income proxied by total expenditure.

- AVYSED: The average years of formal education of the members of the household. 
For the estimation process, LIMDEP Version 7.0 with NLOGIT was used. It is possible to obtain the parameter estimates of three-level nested model with Limited Information Maximum Likelihood (LIML) or the Full Information Maximum likelihood (FIML). It has, however, been shown (and this was observed in the estimation of this model) that FIML yields efficiency gains over LIML (McFadden, 1981; Amemiya, 1981; Gertler and van der Gaag, 1990).

\section{Results and Interpretations}

Table 1 presents the output of the estimated three-level nested model of demand for healthcare services in the Nsukka LGA.

The results are divided into two sets of parameter estimates. The first, Set A, is the set of estimated utility function parameters with the Pseudo $R^{2}$. Set B is the set of estimated inclusive-value parameters. The $t$-ratios and $p$-values are also included. The estimated coefficients in Set A reflect the impact of the variables on the utility that households derive from seeking care from healthcare facilities.

There are several methods of interpreting estimates of probability models (Long, 1997). However, it has been noted that the easiest and

Table 1: Parameter estimates of a three-level nested logit model of demand for healthcare services

\begin{tabular}{lrrr}
\hline Variable & Parameter estimate & $t$-ratio & $p$-value \\
\hline Set A: Utility function & & & \\
parameter estimates & & & \\
DISTANCE & -0.108 & -3.062 & 0.0022 \\
LOGINC & 0.079 & 3.288 & 0.0010 \\
LOGPCFDX & 0.123 & 6.330 & 0.0000 \\
HH_SIZE & -0.115 & -4.644 & 0.0000 \\
SEVERITY & 0.160 & 5.988 & 0.0000 \\
W_TIME & -0.069 & -1.047 & 0.2952 \\
LTMTCOST & -0.051 & -0.852 & 0.3942 \\
NAVYRSED & 0.105 & 6.781 & 0.0000 \\
S_AGE & 0.084 & 5.525 & 0.0000 \\
LOC & 0.660 & 11.240 & 0.0000 \\
Pseudo $R^{2}$ & 0.270 & & \\
Set B: Inclusive-value & & & \\
parameter estimates & & & \\
Branch $\left(1-\sigma_{k}\right)$ & 0.438 & 0.000 & 1.000 \\
Limb $\left(1-\sigma_{j}\right)$ & 0.618 & 0.000 & 1.000 \\
Trunk $\left(1-\sigma_{i}\right)$ & 1.000 & 0.000 & FIXED \\
\hline
\end{tabular}


most useful way is that of odds and odds ratios (Liao, 1994; Hosmer and Lemeshow, 1989, p. 41).

There are ten variables in Set A. The first variable in the set is DISTANCE, measured in kilometres. This is the distance households have to travel to reach the chosen healthcare facility. Obviously, this variable represents a dis-utility to the household that is seeking care. The coefficient on it is, therefore, negative as expected. Statistically, the estimated coefficient of the variable is significant at the usual level of 95 per cent confidence interval. (This same confidence interval is applied in the rest of our hypothesis tests). By taking the anti-log of the coefficient -0.108 we obtain 0.897 . This is the decrease in the odds of seeking healthcare from healthcare facilities for every additional kilometre in distance to a healthcare facility given that a household decided to seek treatment and given that it sought formal care. This result indicates that distance to facilities is a major hindrance to access to healthcare utilization in the area under study.

Log of income (LOGINC) has a positive sign. Its coefficient 0.079 is statistically significant as shown by the $t$-ratio or more precisely by the probability value $[p$-value $=0.0010]$. The implication is that when we are comparing the effect of income on the choice between two healthcare alternatives, say $k_{1}$ and $k_{2}$, the odds of choosing one against the other will change by a factor $\exp (0.079)$ for every unit change in the log of income, holding every other variable constant. If, for example, we consider the choice between home care and care in a private hospital, this result indicates that for every additional unit in the log of household income the odds that the household will seek care from a private hospital increases by a factor of $\exp (0.079)$. In other words, richer households have higher odds than poorer ones of seeking healthcare when they are sick. This implies also that low income is likely to be a hindrance to access to healthcare in the area.

The log of per capita food expenditure variable ( $L O G P C F D X)$ also has the expected sign and its parameter estimate of 0.123 is statistically significant. The anti-log is 1.13 . The interpretation is essentially the same as in $\log$ of income but here it applied to food expenditure. Every 1 per cent increase in $\log$ of food expenditure increases the odds of seeking healthcare from a facility by 1.13 per cent.

The demographic variable, household size $\left(H H_{-} S I Z E\right)$ has a negative coefficient. The magnitude is statistically significant. The negative sign is also consistent with expectation. The coefficient is $\exp (-0.115)$ and the anti $\log$ is 0.891 . Large households seem to decrease the odds of seeking healthcare. In other words, the larger the household is, the less likely that a sick member of that household will be able to utilize a medical facility. 
The severity of illness variable (SEVERITY) has a positive sign. This conforms to a priori expectation. The magnitude of the coefficient is $\exp (0.160)=1.73$. It is also statistically significant showing that severity is a major consideration for households when they seek healthcare services. An increase in the number of days one is unable to perform one's normal duties due to sickness will naturally prompt the household to seek medical attention.

Waiting time (W_TIME) has the expected negative sign but it appears to be an insignificant factor in healthcare decision in the area under study. Some other empirical studies have found a similar result (for example, Acton, 1975; Akin et al., 1986). The non-significant influence of this variable on the demand for healthcare can be understood from the perspective that while a consumer may consider the time spent in obtaining treatment as important, he or she may place a higher premium on other qualities of the facility. For example, a consumer may consider the time spent waiting for treatment as secondary to the quality of drugs, and attention obtained when he or she eventually gets treated. It may also imply that because of the number of facilities in the area patients do not have to wait long before they get treated. The latter may be more likely since from the descriptive statistics it was observed that most patients did not have to wait more than 45 minutes to obtain treatment.

The average years of formal education (NAVYRSED) of the household shows up as a positive and significant factor in the demand for health services from the sample included in this study. The average increase in the odds of seeking care from a facility increases by a factor of $\exp (0.105)=1.11$ as the average years of formal education of the household increases. However, some other studies have found education to be a non-significant factor in a household's healthcare utilization decisions. For example, Gertler and van der Gaag (1990) using a nested multinomial logit model found this demographic variable insignificant in the decision of the individual patient to seek formal care in rural Côte d'Ivoire. Ellis and Mwabu (1991) found it to have a negative relationship with reporting illness while it has a positive relationship with the decision to seek formal treatment. It is arguable that the insignificance of the variable in the Ivorian study is due to the very low level of education in the area. (The average length of years of education for individuals in the sample was about one year, with little variation). This may be contrasted with a household average of 7.16 years of formal education in the sample from the Nsukka LGA used in this study. Therefore, the contrast in the findings may not be altogether surprising.

The log of treatment cost variable (LTMTCOST) represents the financial cost to the household of seeking healthcare for the individual member of the household. This variable was expected to be negative and 
significant but it turns out to have the expected sign but statistically insignificant as noted in the review of literature. While it is economically reasonable to expect cost of obtaining treatment to be a hindrance to healthcare utilization quite a number of studies have found this variable insignificant. One possible explanation for this aberrant behaviour is that the healthcare market suffers from information asymmetry between the buyer and the supplier. Consumers often rely completely on the prescriptions of the healthcare provider. In such an environment it is easy for consumers to use cost as the parameter for quality of drugs. In such a situation prices may give contradictory signals to buyers. Higher prices may be seen as indicative of greater quality of care. In that case patients may attach a higher value to drugs that cost more financially. This may attenuate the consideration for cost.

The age of the sick person $\left(S_{-} A G E\right)$ appears to influence the healthcare decisions of the household significantly. The model shows that there are greater odds by a factor of $\exp (0.084)=1.09$ in healthcare utilization as age increases. Although this may not be altogether expected, the result is consistent with some other studies that have found greater allocation of resources to working adults who must be in a healthy condition in order to fend for the household and other dependants. The economic sustenance of the household depends on these working adults (World Bank, 1993; Sauerborn et al., 1996).

Location $(L O C)$ is a dichotomous variable which assumes the value of 1 if the household was from the Nsukka urban area and zero otherwise. The coefficient of the dummy is positive and statistically significant. The calculated difference in the odds of a person from the Nsukka urban area and his/her counterpart in the village in seeking healthcare from a facility is $\exp (0.660)=1.93$. This implies that a city dweller is about twice as likely to seek treatment from a facility than a village dweller, judging from our sample. This is consistent with findings from other similar studies. For example, the World Bank Report (1993, p. 69) shows that households living in urban areas seek and obtain healthcare services more often than their counterparts in rural areas.

In general, it can be said that the estimated parameters of the variables included in the model are mostly consistent with economic theory. The findings are equally revealing. They indicate the variables that constitute dis-utilities to healthcare consumption. Higher income households are more likely to seek care from facilities than poor households, older people seem to get treated more than younger people, big household size constitutes a barrier to healthcare consumption, more educated households are more likely to seek care from facilities when they are sick. It is in conformity with expectation that distance would be a hindrance to access to facilities but it is striking that waiting time and 
treatment costs do not seem to be serious barriers to healthcare consumption in the area. This is even more striking when it is considered that the area under study is not an economically wealthy area.

\subsection{The Estimated Inclusive-Value Parameters}

The estimates of the inclusive-value parameters are $\left(1-\sigma_{k}\right)$ and $\left(1-\sigma_{j}\right)$ for the branch and limb levels respectively. The trunk level inclusivevalue parameter $\left(1-\sigma_{i}\right)$ should, obviously, be 1.0 since it is assumed that no other choice is available at this level.

The null hypothesis $(\mathrm{H} 0)$ : $\left(1-\sigma_{k}\right)=0$ was tested using the Wald test. The estimated value $\left(1-\sigma_{k}\right)$ was constrained to 0 but this constraint was obviously rejected. The value must therefore be assumed to be different from zero and different from 1.00. This is a rejection of the multinomial logit model in favour of the nested logit model. It also implies that the model is consistent with random utility maximization. This implies, further, that the decision about which health facility to seek care from is not independent of the prior decision to seek formal or informal treatment. Put in another way, an average household's decision to seek formal care from a healthcare professional or to resort to informal care is influenced by the availability of healthcare facilities. For example, a household may easily decide to consult a medical doctor if a hospital is next door. On the other hand, if the hospital is very far away, or the waiting time is very long, the household might decide to put up with the pain of illness or treat at home until it becomes very severe. Thus, the finding suggests that in the area under survey, access to healthcare facilities may influence people's decision to seek care from healthcare professionals as opposed to treating themselves at home. However, the fact that the inclusive-value parameter estimate at this level is different from 1.00 implies that there is no perfect correlation between any of the choice alternatives.

The hypothesis that the inclusive-value at the limb level $\left(1-\sigma_{j}\right)$ is equal to 0.00 or equal to 1.00 was similarly tested using the same Wald test. The constraints of equality were rejected. This implies that the average household's decision not to seek treatment or to seek treatment (whether from a professional healthcare facility or at home) given that it reported illness is not an independent decision. The decision to seek treatment may be influenced by the decision either to treat at home or to go to a healthcare professional.

Furthermore, as Maddala (1983, p. 73) shows, the values $\sigma_{k}$ and $\sigma_{j}$ on the inclusive value parameters indicate the correlation between the choices made within each subgroup - at the lowest level of choice 
(among facilities) and at the branch level (whether to seek or not to seek treatment). That is to say, these values on the inclusive value parameters provide estimates of the similarity or dis-similarity between the choices made within the subgroups at each level. Thus, for example, if $\sigma_{k}=1$, implying that all the alternatives within the choice-set (e.g. the facilities) are actually identical. In making a choice in this case the household will perceive all the alternatives within this subgroup as if it contains a single alternative. At the same time if the inclusive value $\left(1-\sigma_{k}\right)=0$ it implies that the decision to seek formal care from professional healthcare providers or to seek informal care at home is not influenced by the availability of healthcare providers. It further implies that the error term arising from the utility function of seeking formal treatment does not correlate with the error term from the utility function of seeking informal care.

In more technical terms, if we assume $h$ to represent informal treatment and $f$ to represent formal treatment, the implicit assumption when the inclusive value is 0 is that $\varepsilon_{h f}=0$. That is, the correlation between the error in the decision to seek formal treatment is uncorrelated with the error in the decision to seek informal treatment. From this perspective, testing for the validity of the assumption of independence from irrelevant alternatives (IIA) is equivalent to testing that $\sigma_{k}$ and $\sigma_{j}$ are significantly different from 1. In the present model, using the Wald test, the values obtained for both $\sigma_{k}$ and $\sigma_{j}$ are significantly different from 1. Hausman and McFadden (1984) suggested the test of a reverse implication of IIA by eliminating one or more alternatives from the choice set to see if the underlying behaviour would change. If the coefficients remain the same, then it is evidence of the validity of the IIA assumption; if not, it is evidence that the assumption holds. In both cases the result obtained from this model suggests that:

1. the facilities - Public Hospital/Clinic, Private Hospital/Clinic, Traditional Medicine and Pharmaceutical/Patent Medicine stores - are closer substitutes (but not identical) for one another, more than any of these is with home treatment.

2. Formal care (treatment at a facility) and informal care (home treatment) are closer substitutes than the decision to seek care and not to seek care.

The inclusive value at the trunk level, as noted earlier, is obviously a unit and it is a fixed value. There is really no choice made at this level and the probability of reporting sick is 1.00 , since the model estimated the sample of only the sick. The inclusion of a non-sick group in the model would result in extending the model to a fourth level which we did not consider necessary. 
A major test of the correct specification of the model is that the inclusive-value parameters should lie in the range of zero to one. Maddala (1983, p. 73) states that if the estimated inclusive-value parameters lie outside the unit interval, we should view this as evidence of a specification error and re-examine the model. Fortunately, the model that was estimated does not seem to have this flaw as the inclusive-values lie within the unit interval. One may therefore conclude that the model does not contain a specification error. To confirm these results, the inclusive-value parameter estimates were constrained to equal one. Under the Wald test this constraint was rejected. Thus we conclude that the values are different from one. The pseudo $R^{2}$ is low (approximately 0.27 ). This statistic is not usually high in probability models unlike in linear models. The pseudo $R^{2}$ in logit models do not have the same meaning of explained-unexplained as in OLS regressions (Hamilton, 1998, p. 231).

\subsection{Post Estimation Analysis}

Figure 2 shows the plot of income against predicted probabilities of choosing a given type of healthcare. In order not to clump up the space the options No Care, and Traditional Medicine with relatively small numbers have not been included in the chart. On the vertical axis are the predicted probabilities while the horizontal axis is the different categories of income.

What seems obvious from the graph is that at almost all levels of income, the predicted probability of home care is much lower than that of any of the other three. Furthermore, controlling for every other variable, it appears that at almost all levels of income the probability of utilizing either a private hospital or clinic, and patent medicine is higher than that of public health facilities.

Figure 2: Household income and predicted probabilities

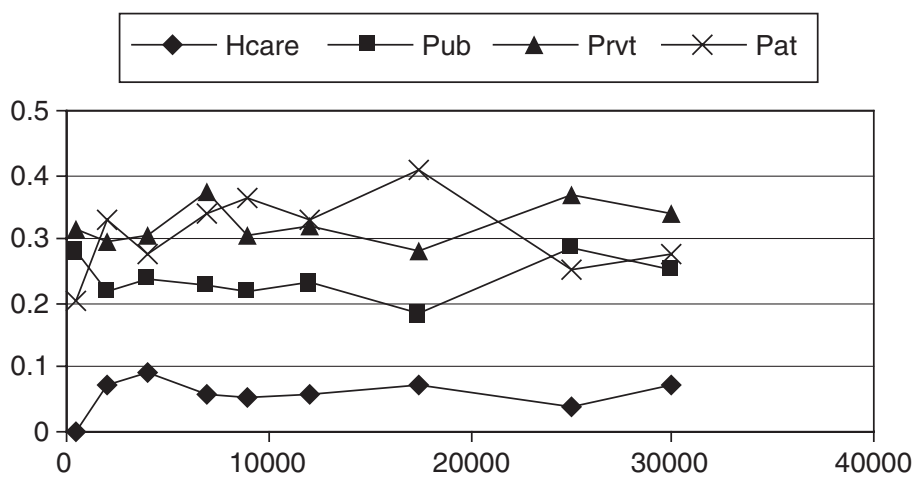


Altogether, the graph seems to suggest that although statistically significant, the influence of income in the choice of medical facility in the area surveyed is not very decisive or seems to have been attenuated by the influence of some other factors. It was expected that the predicted probabilities especially for the private healthcare providers would rise steeply as income increases while the probability of choosing the home care option would fall as income rises. That this does not happen may be an indication that both the rich and poor delay treating their illness until it becomes sufficiently serious to prevent them from carrying out their normal duties. Alternatively, it may mean that both the rich and poor resort to first aid at home before consulting a medical facility. In the event of any of these, the impact of income on the demand for healthcare may be reduced though not altogether removed. In such a situation other variables may assume greater importance than income in the utilization of medical facilities. This suggestion is reinforced by the graph of severity against predicted probability of healthcare utilization shown below.

Figure 3 plots the predicted probabilities of utilizing the services of a public health facility, private health facility and patent medicine dealer on the vertical axis. The levels of severity of illness are shown on the category axis. The levels of severity range from zero to 30 representing the number of days the patient was unable to carry out normal duties.

As can be seen from the graph, the probability of consulting a public facility rises relatively sharply as the level of severity of the illness increases. At zero level of severity, the probability is about 0.20. As the level of severity increases, the probability of consulting a public healthcare provider increases steadily, tending towards 0.50 as the level of severity approaches the maximum.

On the contrary, the probability of patronizing a pharmacist or a patent medicine dealer starts off at a little above 0.40 when severity is

Figure 3: Severity and predicted probabilities

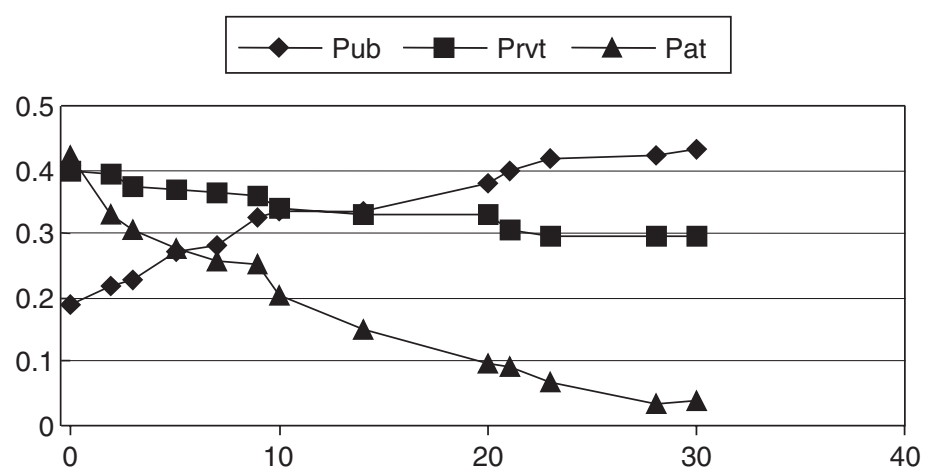


zero. It declines steadily as the level of severity increases; reaching almost zero as the level of severity approaches its limit. This trend suggests the "firstaid' importance of this group of healthcare suppliers in the Nsukka LGA.

It is surprising, however, that the probability of consulting a private healthcare provider shows a negative trend. It declines slowly from 0.40 to 0.30 as severity increases from zero to maximum. The expectation was that based on their often-claimed higher healthcare delivery efficiency, patients would resort to this group of providers for faster results on their health condition. That this is not the case suggests a closer investigation into the relative efficiencies of the different categories of healthcare providers operating in this area.

The positive influence of age on the utilization of healthcare seems rather surprising but parallels the findings of some research reports from other places. For instance, Gertler and van der Gaag (1990, pp. 92-93) reported a similar mode of healthcare seeking behaviour among the Peruvian population. This raises a very crucial question about equity in intra-household resource allocation. Is the assumption of equality in intra-household resource allocation that is often made in cross-sectional studies really justified? Do certain cultural and social norms place the weaker members of some households in a disadvantageous position in the allocation of household resources? These questions require further investigation.

Closely connected with the effects of level of education and income on healthcare demand decisions is the negative effect of large household size. Educated households generally tend to be smaller in size than households with low education. Household size negatively impacts on the utilization of healthcare facilities in the area. This is consistent with the findings of similar empirical studies (e.g. Ellis and Mwabu, 1991). It is possible that this negative relationship arises from the fact that in a large household less attention may be given to the needs of individuals than in a small household. Expenditure per capita is likely to fall as the size of the household increases. A large household is more likely to be poorer, especially if children predominate the population. However, a larger household is likely to be more efficient than a small-sized household in consumption. But this gain in efficiency may not offset the drop in average per capita for every marginal increase in size of the household.

\section{Conclusion}

The nested logit model seems clearly to be an appropriate model for studying the pathways of households' healthcare decision processes. Its 
superiority to a number of other models that econometricians have used in studying healthcare demand appears obvious.

From the estimated model, severity seems to assume a central consideration in the whole question of demand for healthcare and the choice of facility. Consequently, the facility people seek care from seems to depend to a great extent on the level of illness. The emergence of this variable as a factor of central importance seems to have diminished the importance of income in the demand for healthcare services.

The dependence on this criterion for seeking treatment may have very undesirable social consequences. For one, some illnesses have mild symptoms and a very short warning period. Such may result in sudden deaths. For another, the near-total dependence on patent medicine to treat illnesses that are considered not severe may lead to further health complications. It also suggests that primary healthcare services should be given closer attention by the public policy-maker than was the case at the time of data collection. Such a policy focus on primary healthcare will help in early detection of serious illness symptoms and early referral of patients to curative health centres. It may also be useful to train and integrate the patent medicine dealers within the framework of the primary healthcare system in the area. Such integration would mandate the patent dealers to refer patients to hospitals and clinics after giving them the first aid treatment.

The category of people who buy healthcare from the traditional medicine practitioners (shown elsewhere as descriptive statistics) raises a fundamental question about the continued neglect of this group of healthcare suppliers. Although they constitute a small part of the medical market, most of their clients came from the upper income quintiles and the well educated. The fact that the cost of treatment in these traditional health facilities seems to be the highest, and yet they continue to get clients indicates that they have relevance in the healthcare system. The periphery position of this group in the present health system needs to be reviewed by health policy-makers.

\section{References}

Acton, J.P. (1995), "Non - Monetary Factors in the Demand for Medical Services: Some Empirical Evidence" Journal of Political Economy, Vol. 83, No. 3, pp. 595-614.

Agresti, A. (1990), Categorical Data Analysis, John Wiley, New York.

Ajayi, S.I. (2001), External debt capital flight and growth in Nigeria, A Paper Presented at an International Conference on Sustainable Debt Strategy for Nigeria Abuja, May 17-18, 2001. 
Akin, J. (1981), 'The Demand for Children Health Services in the Phillipines', Social Science and Medicine, Vol. 15, pp. 247-57.

Akin, J., D.K. Guilky, C. Griffin and B.M. Popkin (1986), 'The Demand for Primary Health Care Services in the Bicol Region of the Phillipines', Economic Development and Cultural Changes, Vol. 34, No. 4, pp. 755-82.

Aldrich, J.H. and F.D. Nelson (1984), Linear Probability, Logit and Probit Models, Sage, Beverly Hills, CA.

Amemiya, T. (1981), 'Qualitative Response Models: A Survey', Journal of Econometric Literature, Vol. XIX, pp. 1483-1536.

Amemiya, T. (1985), Advances Econometrics, Basil Blackwell: Oxford.

Ayogu, M.D. (1999). 'Before Prebendalism: A Positive Analysis of Core Infrastructure Investment in a Developing Fiscal Federalism', African Development Review, Vol. 11, No. 2, pp. 169-98.

Bartholome, C. and S. Vosti (1995), 'Choosing between Public and Private Healthcare: A Case Study of Malaria Treatment in Brazil', Journal of Health Economics, Vol. 14, pp. 191-205.

Cramer, J.S. (1991), The Logit Model, E. Arnold, New York.

Deaton, A. (1997), The Analysis of Household Survey: A Microeconometric Approach to Development Policy, Baltimore: The John Hopkins University Press.

Deaton, A. (1998), The Analysis of Household Surveys: A Microeconomic Approach to Development Policy, The Johns Hopkins University Press, Baltimore, MD.

Domencich, T.A., and D. McFadden (1975), Urban Travel Demand: A Behavioral Analysis, North-Holland Publishing Company, Amsterdam.

Dor, A., P. Gertler and J. Van der Gaag (1987), 'Non Price Rationing and the Choice of Medical Care Provided in Rural Côte d'Ivoire', Journal of Health Economics, Vol. 6, pp. 291-304.

Dow, W.H. (1996), 'Unconditional Demand for Health Care in Côte d'Ivoire', World Bank LSMS Working Paper No. 127, Washington, DC.

Egwu, S. (1998), Structural Adjustment, Agrarian Change and Rural Ethnicity in Nigeria, Nordiska Afrikainstitutet, Uppsala.

Ellis, R. and G. Mwabu (1991), 'The Demand for Outpatient Medical Care in Rural Kenya', mimeo, Department of Economics, Boston University, Boston, MA. 
Gertler, P., L. Locay and Sanderson (1987), “Are user fees regressive? The welfare implications of health care financing proposals in Peru" Journal of Econometrics, Vol. 36, pp. 67-88.

Gertler, P. and J. van der Gaag (1990), The Willingness to Pay for Medical Care: Evidence from Two Developing Countries, The Johns Hopkins University Press, Baltimore, MD.

Green, R.H. (2001), Global debt, the low income quadrant and the case of Nigeria, A Paper Presented at an International Conference on Sustainable Debt Strategy for Nigeria. Abuja, May 17-18, 2001.

Greene, W.H. (1993), Econometric Analysis (2nd edn), Macmillan, New York. Greene, W.H. (1998), LIMDEP Version 7.0. Econometric Software, Plainview, NY.

Grossman, M. (1972), 'On the Concept of Health Capital and the Demand for Health', Journal of Political Economy, Vol. 80, pp. 223-55.

Gujaratti, D. (1993), Basic Econometrics (3rd edn), McGraw Hill, New York.

Hamilton, L.C. (1998), Statistics with STATA 5, Pacific Grove: Duxbury Press.

Hausman, J. and D. McFadden (1984), 'Specification Tests for the Multinomial Logit Model', Econometrica, Vol. 52, No. 5, pp. 1219-39.

Heller, P.S. (1982), 'A Model of the Demand for Medical and Health Services in Peninsular Malaysia', Social Science and Medicine, Vol. 16, pp. 267-84.

Hosmer, D.W. and S. Lemeshow (1989), Applied Logistic Regression, John Wiley, New York.

Johnston, J. and J. Dinnardo (1997), Econometric Methods (4th edn), McGraw Hill, New York.

Koutsoyiannis, A. (1977), Theory of Econometrics (2nd edn), Macmillan, Basingstoke.

Kpakol, M. (2001), Debt management and market opportunity: a focus on Nigeria, A Paper Presented at an International Conference on Sustainable Debt Strategy for Nigeria, Abuja, May 17-18, 2001.

Liao, T.F. (1994), Interpreting Probability Models: Logit, Probit and Other Generalized Linear Models, Sage, Thousand Oaks, CA.

Long, S. (1997), Regression Models for Categorical and Limited Dependent Variables, Sage, Thousand Oaks, CA. 
Mackinnon, J. (1995), 'Health as Informational Good: The Determinants of Child Nutrition and Mortality during Political and Economic Recovery in Uganda', WPAS/95-9 Centre for the Study of African Economies, Oxford University.

Maddala, G.S. (1983), Qualitative Variables in Econometrics, Cambridge University Press, Cambridge.

Manning, W., J. Newhouse, N. Duan, E. Keeler, B. Benjamin, A. Leibowitz, M.S. Marquis and J. Zwanziger (1987), 'Health Insurance and the Demand for Medical Care: Evidence from Randomized Experiment', American Economic Review, Vol. 77, No. 3, pp. 251-77.

McFadden, D. (1981), 'Econometric Models of Probabilistic Choice', in C.F. Manski and D. McFadden (eds.), Structural Analysis of Discrte Data with Econometric Application (pp. 198-272). MIT Press, Cambridge, MA.

McGuire, A., J. Henderson and G. Mooney (1987), The Economics of Health Care, Routledge \& Kegan Paul, London.

Mills, A. and K. Lee (eds.) (1993), Health Economics Research in Developing Countries, Oxford University Press, Oxford.

Mukherjee, C., H. White and M. Wuyts (1998), Econometrics and Data Analysis for Developing Countries, Routledge, London.

Musgrove, P. (1983), 'Family Health Care Spending in Latin America', Journal of Health Economics, Vol. 2, No. 3, pp. 245-58.

Mwabu, G.M., (1984), “A Model of Household Choice among Medical Treatment Alternatives in Rural Kenya" (unpublished PhD Thesis) Boston University.

Mwabu, G. (1986), 'Health Care Decisions at Household Level: Results of a Rural Health Survey in Kenya', Social Science and Medicine, Vol. 2, No. 3, pp. 315-319.

Mwabu, G., M. Ainsworth and A. Nyamete (1993), 'Quality of Medical Care and Choice of Medical Treatment in Kenya: An Empirical Analysis', Journal of Human Resources, Vol. XXVIII, No. 4, pp. 838-62.

Obadan, M.I. (2001), Towards Nigeria's sustainable debt strategy, A Paper Presented at an International Conference on Sustainable Debt Strategy for Nigeria Abuja, May 17-18, 2001.

Ogunbekun, I. (1991), 'Which Direction for Health Care in Nigeria', Health Policy and Planning, Vol. 6, No. 3, pp. 254-61. 
Pearce, T. and T. Falola (1994), Child Health in Nigeria, Avebury, Aldershot.

Praise, S. and H. Houthakker (1971), The Analysis of Family Budgets, Cambridge University Press, Cambridge.

Sauerborn, R., A. Adams and M. Hien (1996), 'Household Strategies to Cope with the Economic Costs of Illness', Social Science and Medicine, Vol. 43, No. 3, pp. 291-301.

Scott, C. and B. Amenuvegbe (1990), Effect of Recall Duration on Reporting of Household Expenditure: An Experimental Study in Ghana; Social Dimension of Adjustment in Sub-Saharan Africa. Working Paper 6, Washington D.C.: World Bank.

Soludo C.C. (2001), Debt, poverty and inequality: towards an exit strategy for Nigeria and Africa, A Paper Presented at an International Conference on Sustainable Debt Strategy for Nigeria Abuja, May 17-18, 2001.

Vogel, R. (1988), Cost Recovery in the Health Care Sector: Selected Country Studies in W. Africa, World Bank, Washington, DC.

Wagstaff, A. (1986), 'The Demand for Health: Theory and Applications', Journal of Epidemiology and Community Health, Vol. 40, pp. 1-11.

World Bank (1993), World Development Report 1993, Oxford University Press, New York. 